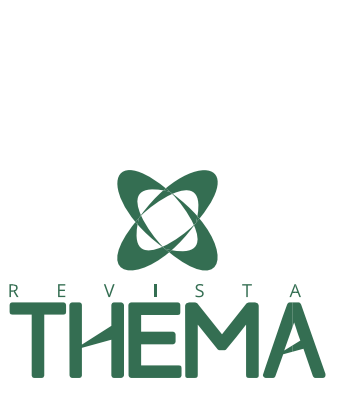

\title{
LINO: JOGO ELETRÔNICO PARA AUXILIAR NA EDUCAÇÃO AMBIENTAL DE CRIANÇAS EM IDADE ESCOLAR
}

\section{LINO: ELECTRONIC GAME TO ASSIST IN ENVIRONMENTAL EDUCATION OF SCHOOL AGE CHILDREN}

Aldo Nascimento Pontes; Israel Freitas Mendes; Maria das Graças J. M. Tomazela ${ }^{1}$

\section{RESUMO}

O caráter lúdico dos games, nas últimas décadas, tem mostrado seu rico potencial na dinamização de processos de ensino-aprendizagem. Este trabalho tem por objetivo apresentar os resultados de uma pesquisa, realizada em 2016, que desenvolveu um game eletrônico para auxiliar na Educação Ambiental de crianças em idade escolar. Assim, por meio de uma pesquisa experimental, desenvolveu-se e implementou-se o jogo Lino, o qual foi submetido a uma avaliação de funcionalidades por um grupo de crianças de uma escola pública. Os resultados mostraram que o Lino representa um caminho lúdico, agradável e didático para expandir a conscientização e a atitude das crianças sobre a questão ambiental.

Palavras-chave: Meio ambiente; Infância; Jogos eletrônicos.

\begin{abstract}
The playfull character of electronic games over the past decades has shown a rich potential in boosting the teaching-learning process. This work aims to present the results of a research that developed an electronic game to support the Environmental Education of scholar aged children. Thus, by means of an experimental research, the Lino game has been developed and implemented, as well as submitted by a functionality assessment. The results has showed that the Electronic Game Lino represents a playfull, pleasant, and didactic way to broaden the awareness and attitude about environmental issues.
\end{abstract}

Keywords: Environment; Childhood; Electronic games.

\section{INTRODUÇÃO}

O alto nível de desenvolvimento tecnológico atingido pela humanidade nos últimos três séculos, resultante da busca desenfreada pelo domínio das formas de produção e controle das reservas naturais, contribui também para graves problemas ambientais que ora vivenciamos. Assim, um dos grandes desafios da humanidade nesta $2^{a}$ década do século XXI é encontrar uma saída capaz de superar os impactos decorrentes da ação humana no meio ambiente, enfrentando o desafio de promover o desenvolvimento de maneira sustentável.

\footnotetext{
${ }^{1}$ FATEC - Faculdade de Tecnologia de Indaiatuba, Indaiatuba/SP - Brasil.
} 
Um caminho para isso tem sido a promoção de uma Educação Ambiental que, no Brasil, de acordo com a Política Nacional de Educação Ambiental, lei 9.795 de 1999, consiste em processos por meio dos quais o indivíduo e a coletividade constroem valores sociais, conhecimentos, habilidades, atitudes e competências voltadas para a conservação do meio ambiente, bem de uso comum do povo, essencial à sadia qualidade de vida e sua sustentabilidade. (BRASIL, 1999).

Atualmente as informações sobre as questões ambientais são mais acessíveis, o que desperta uma percepção ecológica dos entraves que o meio ambiente vem enfrentando, porém é por meio de uma prática reflexiva mais sistemática que essa conscientização pode resultar em uma mudança de atitude, daí a relevância de uma educação de caráter ambiental. (SILVA; CRISPIN, 2011).

Nessa perspectiva, entende-se que, se por um lado o avanço tecnológico nos legou uma série de problemas ambientais, por outro pode contribuir sobremaneira para processos educativos próprios de uma Educação Ambiental, por oferecer uma série de possibilidades interativas, seja por meio de filmes, sites, redes sociais, jogos.

No campo educacional, que concentra a maioria dos usuários de modernos dispositivos tecnológicos (crianças, adolescentes e jovens), a inserção de ferramentas, tais como: softwares educacionais, jogos eletrônicos, aplicativos para celular, Internet, etc., como metodologia alternativa à tradicional, pode complementar os métodos tradicionais de ensino, sobretudo pelo aspecto lúdico que são característicos dessas ferramentas.

Assim, este trabalho tem por objetivo apresentar os resultados de uma pesquisa que desenvolveu 0 Lino, game eletrônico para auxiliar na Educação Ambiental de crianças em idade escolar, contribuindo assim para a conscientização e a preservação do meio ambiente.

\section{REVISÃO DA LITERATURA}

Nesta seção são apresentados estudos que possuem relação com o trabalho desenvolvido. 0 levantamento realizado foi orientado pela busca de pesquisas científicas ou tecnológicas que têm em seus objetivos o desenvolvimento/implementação de tecnologias para a Educação Ambiental, sobretudo aquelas voltadas à educação de crianças e adolescentes.

O trabalho Ilha e Cruz (2006) teve por objetivo desenvolver um projeto para a inserção de jogos em sala de aula. Para isso, foram analisados 6 diferentes jogos: Age of Empires II, AgeofMytholoy, Praetorians, Caesar III, Streetwars: ConstructorUnderworlde Simcity. Como resultado da inserção do projeto na escola, ficou evidente a motivação do aluno por estar fugindo do lugar-comum da sala de aula, assim como também percebeu-se dificuldades de discentes e docentes em envolver-se com essa nova proposta de trabalho.

Criar um simulador de uma fazenda foi o objetivo do trabalho de Silva e Passerino (2007). No projeto desenvolvido, os pesquisadores possibilitaram aos usuários atuar no gerenciamento da produção dessa, oferecendo assim uma ferramenta eficiente de auxílio ao processo de ensino e aprendizagem. Os resultados mostraram que, com a ferramenta criada, os alunos ficaram mais motivados.

No contexto de um projeto interdisciplinar, Santos Filho et al. (2008) realizaram fizeram uso do jogo denominado Tartarugas para o ensino de temas ligados à Educação Ambiental com crianças em idade 
escolar. Os autores afirmaram que houve aumento significativo das notas dos alunos após o uso do jogo, condição diferente quando a aula se limita ao caráter expositivo.

O trabalho de Loula et al. (2009) teve por objetivo apresentar a modelagem ambiental realizada em um jogo eletrônico educativo chamado Calangos, voltado para o ensino e aprendizagem de ecologia. O jogo Calango trouxe uma melhor compreensão sobre as relações ecológicas estabelecidas entre presa e predador, competição, reprodução animal e cadeia alimentar.

Desenvolver um jogo para usar o fator lúdico na inserção de tecnologias de programação em processos educativos foi o trabalho de Calisto et al. (2010). Com base na análise de sete jogos educativos, os pesquisadores desenvolveram o jogo Litoral Norte Sustentável (LNS), que oferece a possibilidade de percepção e tomada de atitude frente aos diferentes tipos de resíduos: papel, plástico, vidro etc. Decorrente disso, os alunos mostraram um maior interesse e motivação em relação ao processo educativo escolar.

O trabalho de Fantini et al. (2011) teve como objetivo realizar um estudo da aplicação do elemento lúdico na área educacional como um recurso motivador da aprendizagem. Para isso, foi selecionado o Jogo da Reciclagem, desenvolvido pelo Projeto SISGA (Sistema de Informação Aplicado ao Sistema de Gestão Ambiental). Nos resultados, observou-se que a maioria dos alunos passou a identificar corretamente as cores das lixeiras relacionando-as com os devidos materiais e mostraram-se melhor conscientizados sobre a importância da reciclagem para preservação do meio ambiente.

Rodrigues, Camargo e Veraszto (2012) desenvolveram um jogo educativo voltado a Educação Ambiental, para plataforma Android, utilizando a linguagem de programação LUA. De acordo com os autores, a eficácia do jogo foi comprovada nos processos de ensino aprendizagem, gerando uma repercussão positiva em todos os níveis escolares, principalmente no ensino fundamental.

Com o objetivo de fazer uma intervenção no processo de ensino aprendizagem de Educação Ambiental, Ferbek e Vila (2013) desenvolveram o aplicativo Ecoquiz. Com o uso dessa ferramenta, observou-se que $100 \%$ dos professores envolvidos consideraram a atividade positiva nas atividades de sala de aula. Já 93\% dos discentes declaram que gostariam de contar com este tipo de aplicação no processo de aprendizagem.

Ferreira et al. (2014) desenvolveram, implementaram e avaliaram o jogo NiceTown, que aborda o tema da Educação Ambiental. Para essa avaliação, utilizaram uma amostra formada por 40 alunos que foram submetidos a um questionário. A partir disso foi possível comprovar o aumento de interesse em aprender e construir conhecimentos por parte dos estudantes.

O conjunto de pesquisas elencado levou a depreender que é recorrente o uso de tecnologias computacionais, por exemplo jogos eletrônicos, como ferramentas para auxiliar nas práticas de educação ambiental, sobretudo por seu caráter lúdico e dinâmico.

Situando o Lino nesse conjunto, apesar de alguma maneira relacionar-se com todos os trabalhos apresentados em função do tema contemplado e do público alvo abarcado (crianças em idade escolar), entende-se que esse se aproxima mais diretamente dos trabalhos de Silva e Passerino (2007), Rodrigues, Camargo e Veraszto (2012), Calisto et al (2010) e Ferreira et al. (2014), por serem trabalhos que despertaram o interesse e a motivação dos estudantes por meio da ludicidade dos jogos eletrônicos desenvolvidos. 


\section{PROCEDIMENTOS METODOLÓGICOS}

Para atingir os objetivos da pesquisa, inicialmente foi feito um levantamento bibliográfico e, em seguida, uma pesquisa experimental em computação, que consiste na determinação de um objeto de estudo, na seleção de variáveis que sejam capazes de influenciá-lo, na definição dos meios para controlar e observar os efeitos que esta variável manipulada possa produzir no objeto (GIL, 2002).

Para concepção, buscou-se informações em outros jogos e/ou aplicativos que tinham objetivos similares ao do Lino, como: Quiz Sustentabilidade (http://www.smartkids.com.br/jogoseducativos/quiz-sustentabilidade.html); Recycle Roundup (http://www.njogos.pt/recycle_roundup.html); Relacione Reciclagem (http://www.smartkids.com.br/jogos-educativos/relacione-reciclagem.html); Jogo da Reciclagem (http://jogos360.uol.com.br/jogo_da_reciclagem.html); Recycle (http://jogos360.uol.com.br/recycle.html).

Assim, para a materialização do Jogo Lino, seguiu-se um fluxo que compreendeu as seguintes etapas: concepção, desenvolvimento, implementação e avaliação desse por um grupo de controle.

Seguindo os padrões da pesquisa experimental, as variáveis consideradas para a construção do jogo foram: especificidades do sujeito, simplicidade da interface, jogabilidade, ludicidade e objetividade.

Para o desenvolvimento do jogo, utilizou-se a ferramenta HTML 5 por meio do Construct 2. 0 Construct 2 é um motor de jogos criado pela Scirra $L t d$., que tem como foco a criação de jogos bidimensionais.

Para os desenhos, foi utilizada a ferramenta de desenho e edição de imagens Paint Brush da Microsoft, e para edição destes desenhos e imagens a ferramenta profissional de edição de imagens bidimensionais da Adobe Systems, que serviu para auxiliar a ferramenta Paint Brush, que é limitada no tocante à edição de imagens.

Para avaliação do jogo, foi selecionado aleatoriamente um grupo de 43 crianças, na faixa etária entre 8 e 12 anos, distribuídos entre a $3^{a}$ e a $7^{a}$ séries do Ensino Fundamental de uma escola pública municipal de Monte Mor (SP), cidade onde reside um dos pesquisadores.

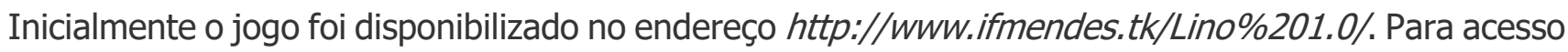
dos usuários, o link do jogo foi divulgado na rede social Facebook, visto essa ser comum ao cotidiano das crianças e seus pais, os quais deveriam orientá-las nesse processo de avaliação.

Assim, após um período de uma semana de utilização do game, essas foram convidadas a responder, presencialmente, um roteiro de perguntas sobre a sua experiência com o jogo.

\section{APRESENTAÇÃO DA FERRAMENTA: CONCEPÇÃO E DESENVOLVIMENTO}

De acordo com o dicionário Michaelis (2015), a primeira definição dada para o nome Lino é canto lamentoso que, na Grécia antiga, pranteava a morte da vegetação. Ainda de acordo com a mitologia grega, Lino era filho do deus Apolo e Terpsicore, era um músico e poeta que foi autor de muitas composições sobre a origem do mundo, astronomia e a natureza das plantas. Assim foi concebido o nome oficial do jogo: Lino, pela relação desse com a temática de interesse deste trabalho, a Educação Ambiental. 


\subsection{Tela de apresentação}

Ao acessar o aplicativo é apresentada uma primeira tela ao usuário. Esta janela é mostrada enquanto os recursos do jogo são baixados, nela contém informações sobre a natureza do projeto.

Após o carregamento do jogo, a tela inicial dá lugar à tela do jogo. Nela há a apresentação do nome do game e do personagem Lino, além de imagens que contextualizam o tema trabalhado no game. Também há três opções para interação do jogador, são elas: Jogar, Como Jogar e Sobre, conforme ilustrado na Figura 1.

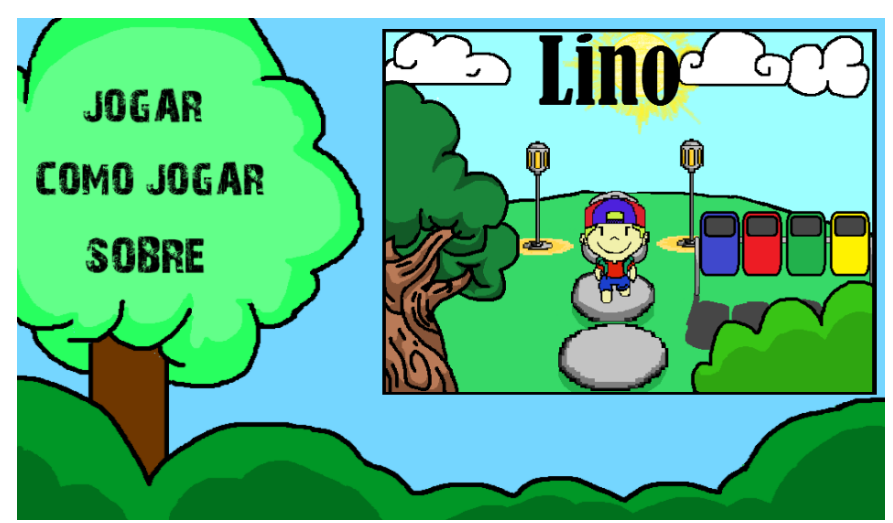

Figura 1: Tela Inicial

\subsection{Tela "Jogar"}

Quando acessada a opção "Jogar", o usuário é redirecionado para tela em que o jogo será iniciado. Nessa tela existem as informações que o jogador irá utilizar para ver seu desempenho na partida, como exemplificado na Figura 2.

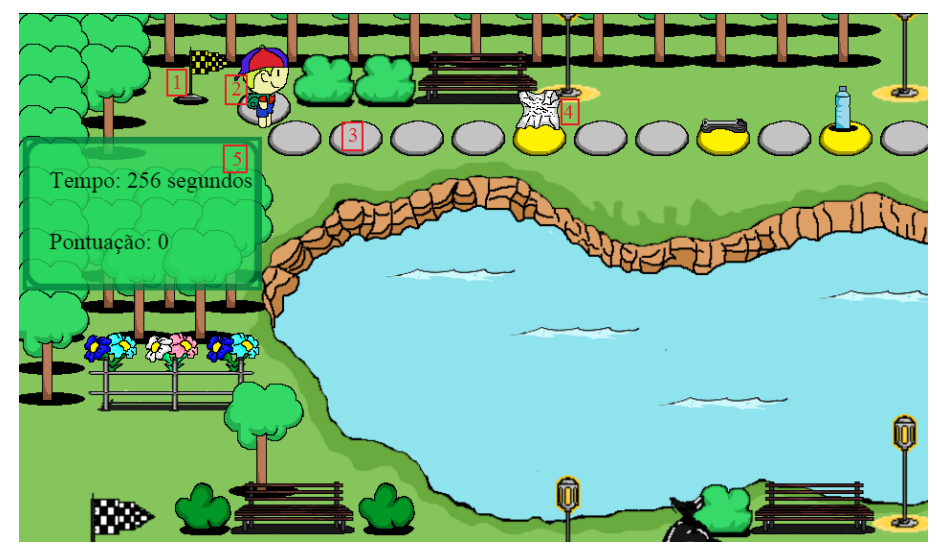

Figura 2: Tela "Jogar"

Para melhor compreensão e controle por parte do jogador, os objetos da tela foram numerados da seguinte forma:

1 - Bandeira Quadriculada em amarelo e preto - Bandeira que marca o ponto inicial de onde o jogador dará início ao trajeto;

2 - Personagem Lino - É a mascote do jogo, que é conduzido pelo usuário e tem a função de representá-lo na exploração e interação com o mapa;

3 - Calçada -A função da calçada no mapa é delimitar o percurso que o jogador deverá percorrer. 
3.1 - Calçada Amarela - Colorida com cor diferente para chamar a atenção do usuário, pois representa que há resíduos a serem coletados sobre elas;

4 - Lixo - Na extensão de todo o percurso do mapa, há quinze tipos de resíduos, eles estão situados no percurso. São materiais de naturezas diversas, como plásticos, papéis, vidros, ferros, metais, borrachas, náilons e orgânicos.

5 - Janela de tempo e pontuação - Nesta tela registram-se as informações de tempo limite do jogo e a pontuação do jogador.

\subsection{Tela "Como Jogar"}

Na tela Como Jogar, Figura 3, apresenta-se ao jogador aquilo que ele precisa saber para jogar. Contém as instruções de configuração de teclas para movimentação e respostas das perguntas.

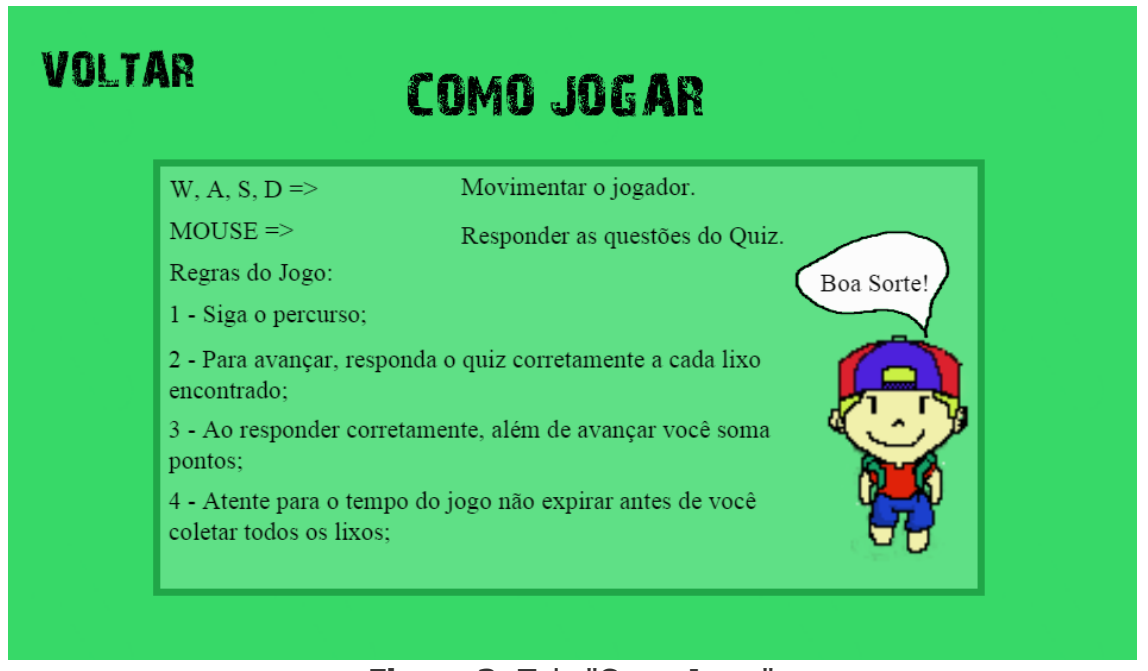

Figura 3: Tela "Como Jogar"

\subsection{Visão geral do mapa do jogo}

Como ponto de partida para a criação do mapa, a inspiração foi o parque ecológico da cidade de Indaiatuba-SP. O cenário do jogo Lino foi modelado com árvores, arbustos, um lago, bancos, luminárias, além de um percurso delimitado por uma calçada de paralelepípedos, mesclando o natural com o urbano. Conforme apresentado na Figura 4.

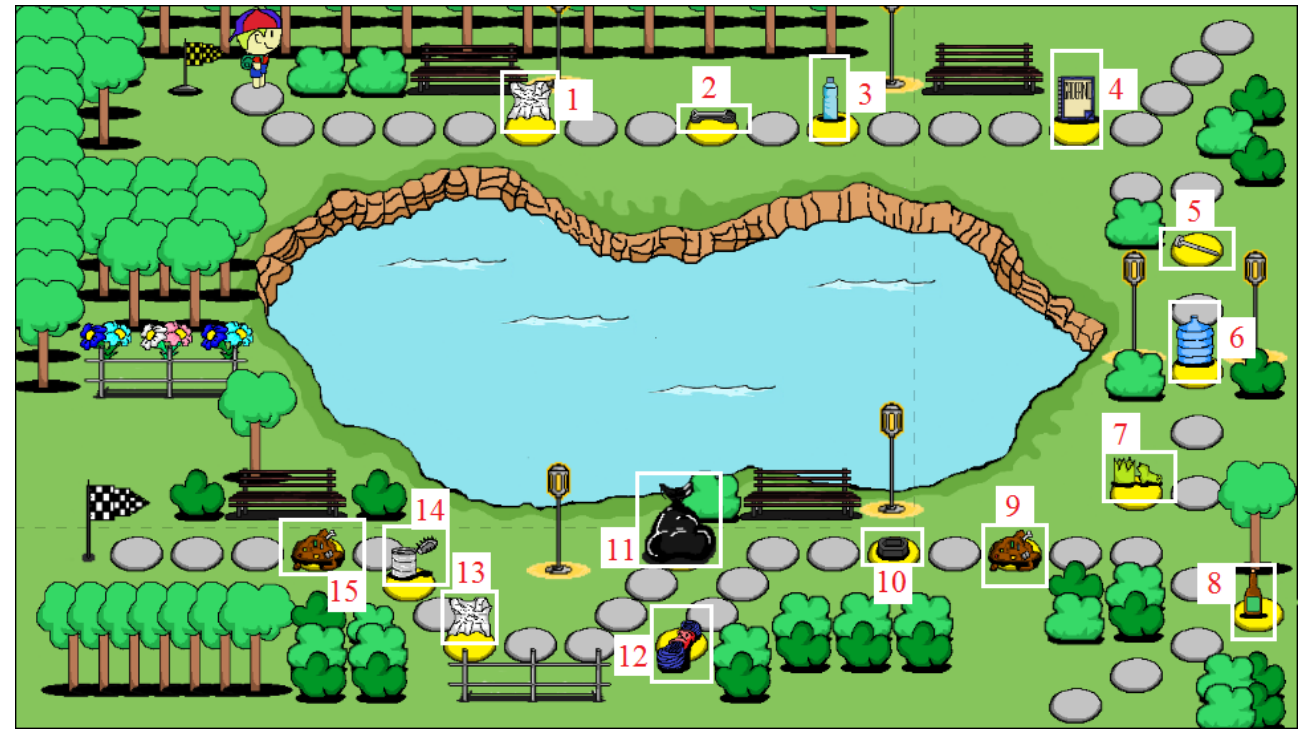

Figura 4: Mapa Geral 
Para melhor detalhar o mapa, foram numerados os resíduos presentes no percurso, sendo:

1 - Papel amassado, tipo de resíduo: papel;

2 - Ferramenta chave de aperto, tipo de resíduo: metal;

3 - Garrafa de água, tipo de resíduo: plástico;

4 - Caderno velho, tipo de resíduo: papel;

5 - Prego, tipo de resíduo: metal;

6 - Garrafa de água para bebedouro, tipo de resíduo: plástico;

7 - Garrafa de vidro quebrada, tipo de resíduo: vidro;

8 - Garrafa de refrigerante, tipo de resíduo: vidro;

9 - Restos de comida, tipo de resíduo: orgânico;

10 - Pneu velho de carro, tipo de resíduo: borracha;

11 - Saco de lixo, tipo de resíduo: orgânico;

12 - Fios de náilon, tipo de resíduo: especial;

13 - Papel amassado, tipo de resíduo: papel;

14 - Lata de alimentos em conserva, tipo de resíduo: metal;

15 - Restos de comida, tipo de resíduo: orgânico;

\subsection{Mascote}

No jogo Lino, a aparência da mascote, Figura 5, foi desenhada respeitando a faixa etária do público alvo, crianças em idade escolar, de modo que representasse o universo infantil do game, fazendo assim uma interação mais amigável com o usuário. Seu nome foi batizado como Lino, assim como o nome do jogo.
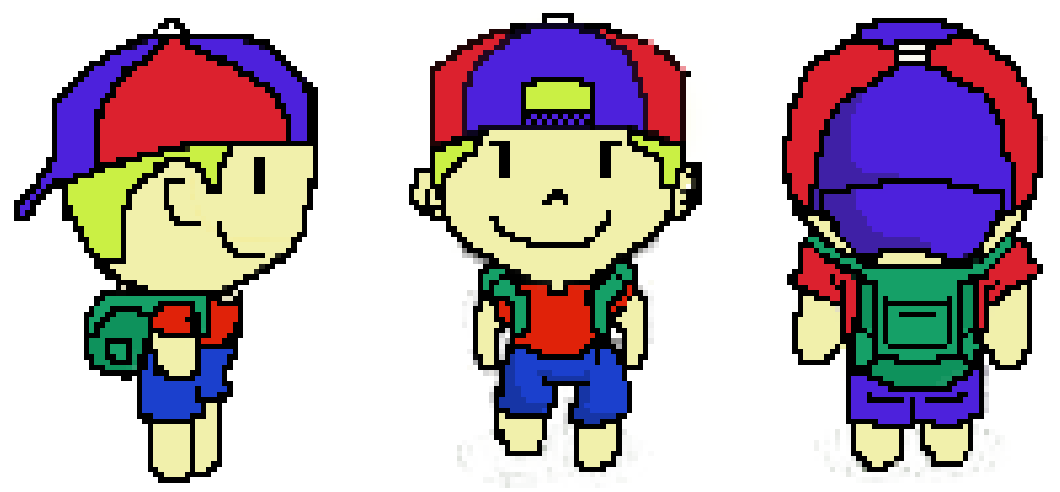

Figura 5: Personagem

\subsection{Avaliação do Lino}

Como apresentado na Figura 6, os sujeitos da pesquisa estão nas seguintes faixas etárias: 7\% tinham 8 anos; 11,6\%, 9 anos; 30,2\%, 10 anos; 25,6\%, 11 anos e 25,6\%, 12 anos. No momento o grupo estava distribuído entre a $3^{a}$ e a $7^{a}$ series do Ensino Fundamental. 


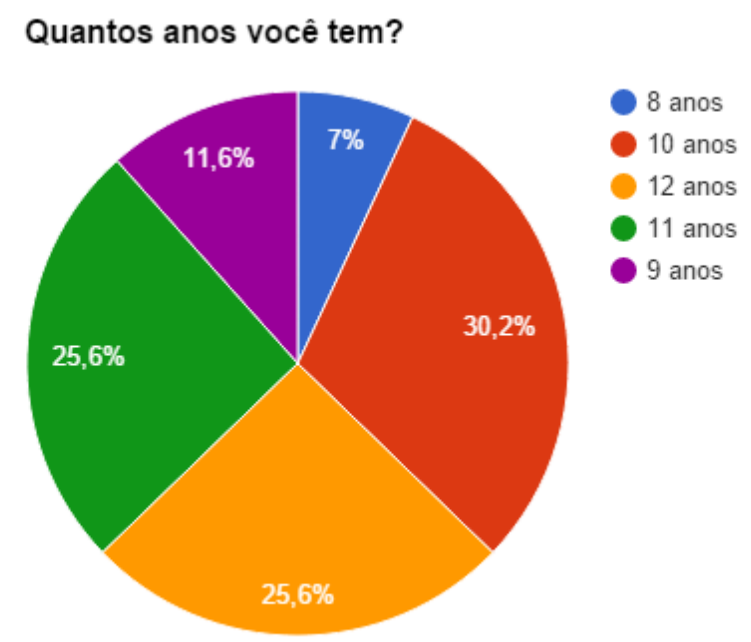

Figura 6: Faixa etária

Sobre a interface do jogo Lino, Figura 7, 95\% responderam que "É fácil de entender, não trava e as imagens são bacanas"; $5 \%$ afirmaram que "Não é fácil de entender, mas não trava e as imagens são bacanas". Não se obteve nenhuma ocorrência em relação às outras alternativas dadas: "É fácil de entender, mas trava e as imagens são bacanas" e "Não é fácil de entender, mas trava e as imagens são bacanas".

\section{Em relação à 'cara' do Jogo Lino, você acha:}
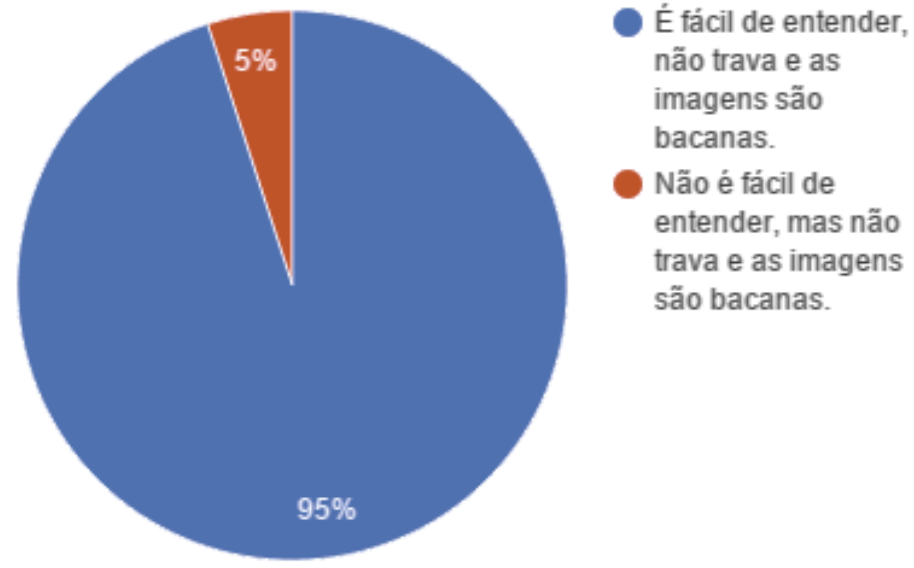

Figura 7: Contagem da Interface do Lino

Outro item avaliado foi a facilidade de jogar o Lino. Na Figura 8, observa-se que, 95,3\% afirmaram que "Sim, é bem fácil, os botões, o game em si, tudo dá para entender" e 4,7\% expressaram que "É mais ou menos fácil, tem alguns problemas nos botões, no game, às vezes não dá pra entender.". Não foi obtida nenhuma ocorrência na alternativa "Não, tem muitos problemas no jogo, é confuso e não dá pra entender." 


\section{É fácil de jogar o Lino?}

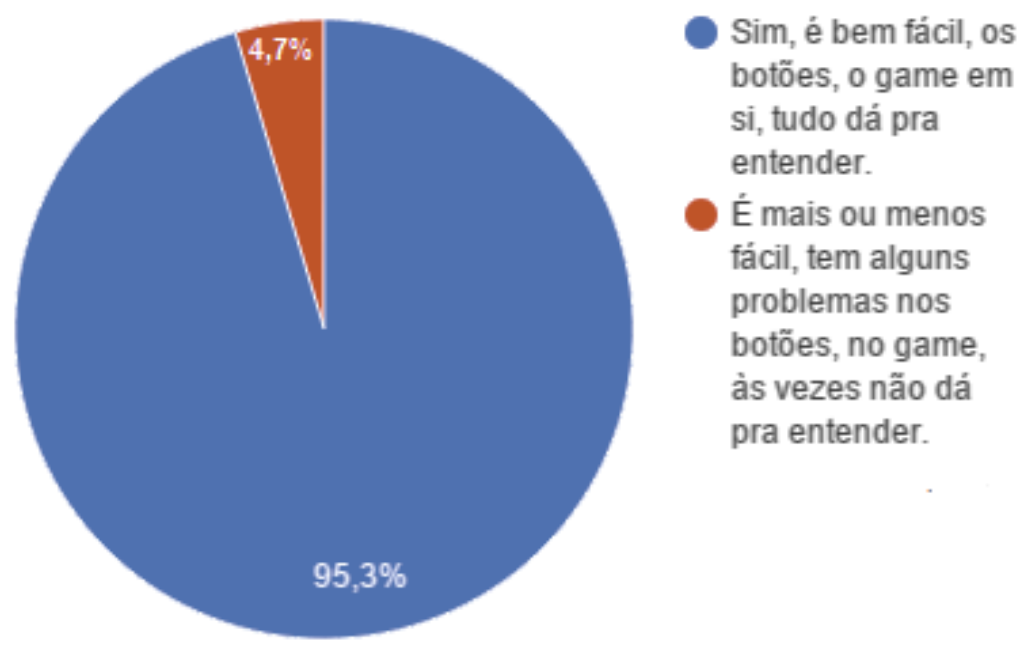

Figura 8: Facilidade de jogar o Lino

Em relação à objetividade das perguntas do quiz do jogo, Figura 9, 93\% afirmaram que "São importantes e fáceis de entender"; 4,7\% disseram que "São importantes, mas não é fácil de entender" e 2,3\% responderam que "São difíceis e não dá muito pra entender". Não foi obtida nenhuma ocorrência em relação à alternativa "Ah, não são muito legais, mas dá pra entender".

\section{Sobre as PERGUNTAS que tem no Jogo Lino, o que você acha?}

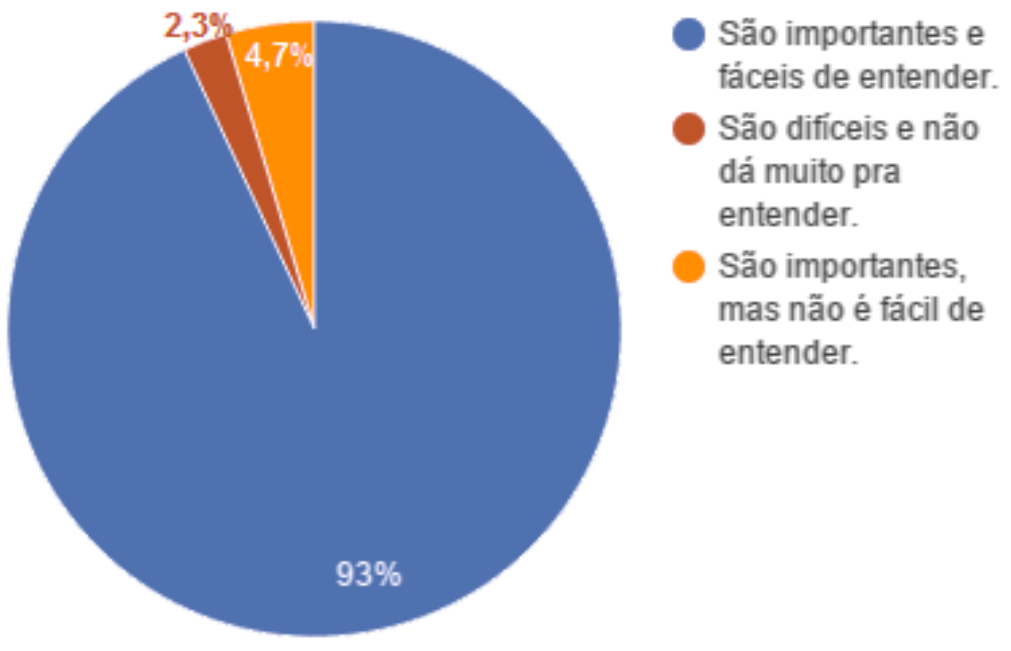

Figura 9: Sobre as perguntas do jogo Lino

Quando questionados se o jogo Lino cumpria com o objetivo de ajudar as crianças a aprenderem mais sobre a Educação Ambiental, como pode ser observado na Figura 10, 86\% afirmaram que "Sim, ele ajuda a entender, sim"; $14 \%$ disseram que "É, ele ajuda mais ou menos". Não houve nenhuma resposta para a alternativa "Não, ele não ajuda a entender de Educação Ambiental". 


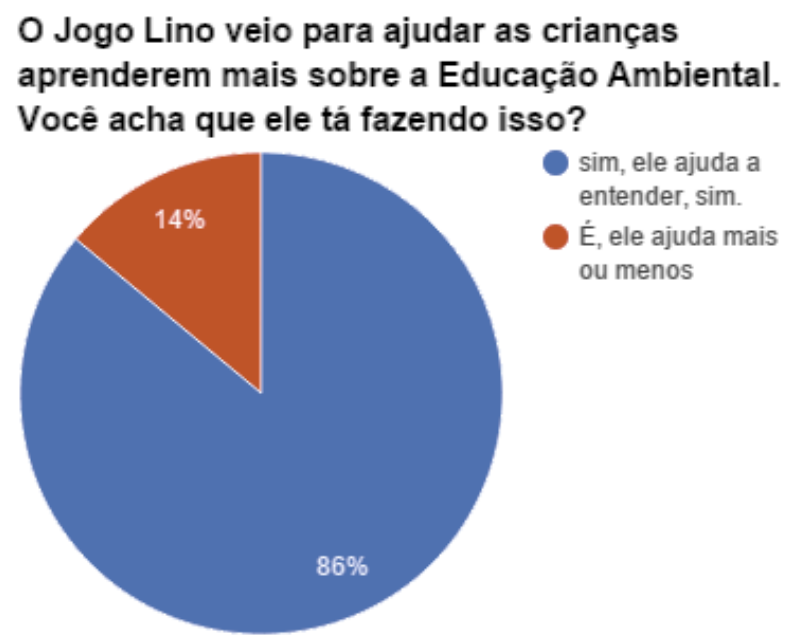

Figura 10: Objetivo do jogo Lino

Conforme ilustrado na Figura 11, 93\% afirmaram que o jogo Lino os ajudou a entender mais sobre como cuidar do meio ambiente, apenas 7\% responderam "não" nessa questão.

\section{O jogo ajudou você a entender mais sobre como cuidar do meio ambiente?}

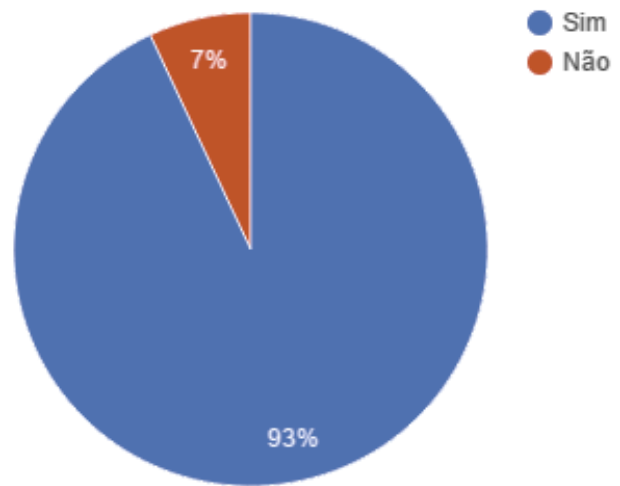

Figura 11: Se o jogo Lino ajuda a entender sobre o meio ambiente

Ao serem convidados a fazerem uma avaliação do jogo Lino como um todo, Figura 12, foi observado que 39,5\% entendem que "É um game muito bom"; 41,9\% disseram que "É apenas bom"; 16,3\% afirmaram que "É razoável" e 2,3\% disseram que "Ah, é um jogo ruim".

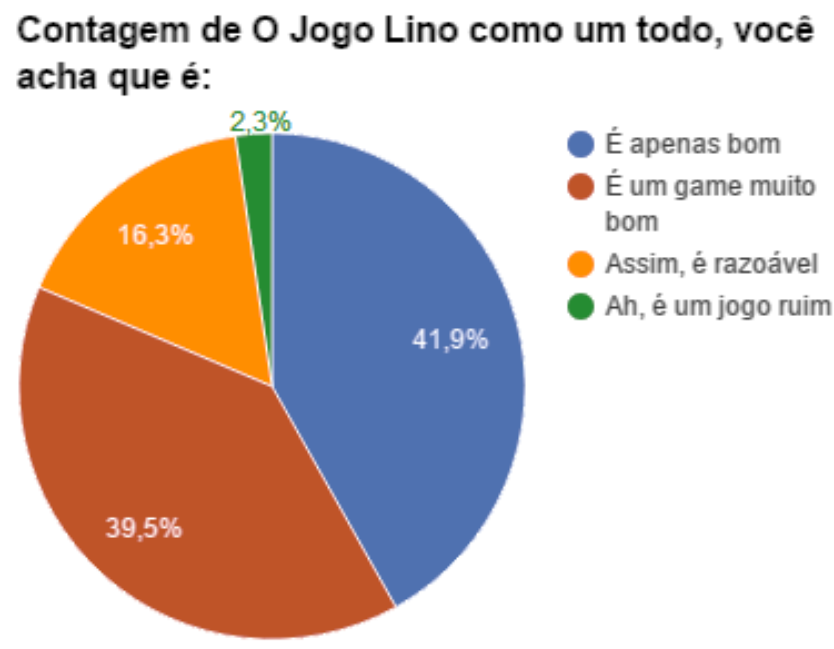

Figura 12: O jogo Lino como um todo 
Para mensurar o caráter oportuno do jogo Lino, foi feita a atribuição de uma nota de zero a dez para o jogo desenvolvido, conforme ilustrado na Figura 13. Assim, foram verificadas as seguintes notas: 9,3\% atribuíram nota $10 ; 30,2 \%$, nota $9 ; 9,3 \%$, nota $8 ; 14 \%$, nota $7 ; 16,3 \%$, nota $6 ; 18,6 \%$, nota 5 e $2,3 \%$, nota 3. Não se observou a ocorrência das notas 1 e 2 . A média das notas atribuídas pelas 43 crianças foi 7.

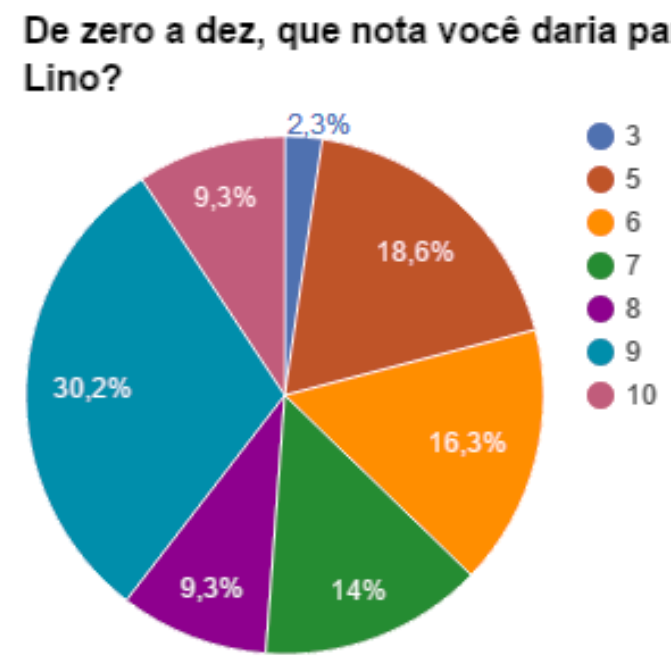

Figura 13: Nota do jogo Lino

Esse conjunto de dados resultante das avaliações dos sujeitos sobre o jogo Lino permite depreender que:

Os usuários, em sua maioria, expressaram que o jogo Lino possui um nível fácil de jogabilidade. Tal situação é resultante da simplicidade nos comandos do jogo, interface agradável e simples, assim como da experiência por parte dos jogadores que avaliaram e testaram o Lino. As avaliações positivas da interface e da jogabilidade contribuíram para confirmar o caráter oportuno do jogo Lino.

No tocante ao caráter didático do jogo, quando avaliado o conteúdo trabalhado por meio das perguntas, foi possível observar que o Lino atingiu seu objetivo de ser um jogo educativo, pois ajudou os sujeitos a entenderem mais sobre como cuidar do meio ambiente, contribuindo assim para Educação Ambiental dos participantes da pesquisa.

Por fim, em suas avaliações, os jogadores confirmaram o bom desempenho do jogo. Condição observada na avaliação do Lino como um todo.

\section{CONSIDERAÇÕES FINAIS}

Para a concepção e desenvolvimento do Lino, foi feito um levantamento de trabalhos de pesquisadores que se empenharam em investigações em que utilizaram ou desenvolveram tecnologias para dinamização de uma Educação Ambiental. Somou-se a isso um mapeamento das tecnologias mais comuns encontradas no mercado que visam contribuir para uma Educação Ambiental. Com base nessas referências foi que se desenvolveu o Lino, com o intuito de oferecer acesso a conhecimentos sobre o Meio Ambiente de maneira lúdica e divertida, atraindo assim a atenção e o envolvimento do público alvo, crianças em idade escolar. 
Nesse sentido, a opção por cores leves e vivas e uma mascote animada teve por intuito promover uma maior identificação e aproximação das crianças com o jogo, viabilizando um fluxo mais dinâmico de aprendizado.

Nos dados coletados do processo de experimentação do sistema, constatou-se um retorno positivo por parte dos envolvidos, que viram no Lino um caminho lúdico, agradável e didático para construir conhecimento sobre Educação Ambiental.

A ferramenta mostrou ser bem-sucedida em seus objetivos propostos, uma vez que $93 \%$ das crianças que avaliaram o Lino ratificaram o seu potencial de contribuir para aprenderem mais sobre como cuidar do meio ambiente, condição que levou que atribuíssem média 7 ao game. Em suma, depreende-se neste exercício de pesquisa que o Lino cumpriu com o seu propósito de contribuir para a conscientização e uma atitude mais proativa frente à questão ambiental.

\section{REFERÊNCIAS}

BRASIL. Ministério da Educação. Secretaria de Educação Continuada, Alfabetização e Diversidade. Educação Ambiental: aprendizes de sustentabilidade. Brasília: Secad, 2007. 109 p.

BRASIL. Lei n. 9795 - 27 de abril de 1999. Dispõe sobre a educação ambiental. Política Nacional de Educação Ambiental. Brasília, 1999.

CALISTO, A.; Barbosa D.; SILVA C. Uma Análise Comparativa entre Jogos Educativos Visando a Criação de um Jogo para Educação Ambiental. In: SIMPÓSIO BRASILEIRO DE INFORMÁTICA NA EDUCAÇÃO, 21, 2010, João Pessoa. Anais..., 2010. Disponível em: <http://www.lbd.dcc.ufmg.br/colecoes/sbie/2010/0080.pdf> Acesso em: 16 mai. 2015.

FANTINI, V. et al. Os jogos virtuais para a educação ambiental no ensino fundamental. Revista Tecnologias na Educação, v.5, n.1, p.1-10, 2011 Disponível em: <http://tecnologiasnaeducacao.pro.br/wp-content/uploads/2011/06/Os-jogos-virtuais-naeduca\%C3\%A7\%C3\%A3o-ambiental2.pdf>Acesso em: 25 abr. 2015.

FERBEK, Guilherme José Vicente; VILA, Paulicia Sabatini. Desenvolvimento de um Aplicativo Visando à Educação Ambiental. In: SIMPÓSIO DE EXCELÊNCIA EM GESTÃO E TECNOLOGIA, 10, 2013, Resende-RJ. Anais..., 2013. Disponível em: <http://www.aedb.br/seget/arquivos/artigos13/52418609.pdf > Acesso em: 25 abr. 2015.

SANTOS FILHO, José Walter. et al. Educação ambiental com objetos de aprendizagem: O Caso Tartarugas. In: SIMPÓSIO BRASILEIRO DE GAMES E ENTRETENIMENTO DIGITAL, 7., 2008, Belo Horizonte. Anais..., 2008. $\quad$ p. 146-149. Disponível em: <http://www.inf.pucminas.br/sbgames08/EBooks/Proceedings-SBGames-GC-2008-Final-EB.pdf >. Acesso em: 25 abr. 2015.

GIL, Carlos Antônio. Como elaborar projetos de pesquisa. 4. ed. São Paulo: Atlas, 2002.

HAMANN, Renan. iOS, Android e Windows Phone: números dos gigantes comparados. Disponível em: $\quad<$ http://www.tecmundo.com.br/sistema-operacional/60596-ios-android-windows-phonenumeros-gigantes-comparados-infografico.htm> Acesso em: 25 mai.2015.

HUIRINZA, Johan. Homo Ludens: o jogo como elemento da cultura. São Paulo: Perspectiva, 2000. 
ILHA, P.C. Abdala e CRUZ, D. Márcia. Jogos eletrônicos na educação: uma pesquisa aplicada do uso do Sim City4 no ensino médio. In: CONGRESSO DA SOCIEDADE BRASILEIRA DE COMPUTAÇÃO - CSBC, 26, 2006, Campo Grande. Anais..., 2006. Disponível em: < http://www.brie.org/pub/index.php/wie/article/view/897/883 >. Acesso em: 25 abr. 2015.

KLEINA, Nilton. 0 que é engine ou motor gráfico?. Disponível em: http://www.tecmundo.com.br/video-game-e-jogos/9263-o-que-e-engine-ou-motor-grafico-.htm> Acesso em 04 nov. 2015.

MICHAELIS: moderno dicionário da língua portuguesa. São Paulo: Companhia Melhoramentos, 2015- (Dicionários Michaelis).

RIOS, Mirivan Carneiro; ORESTES, Neto Zivieri. Educação Ambiental: Aprender e Compartilhar por meio da Mídia Impressa e da Internet. Educação em Foco, 2014. Disponível em: < http://unifia.edu.br/revista_eletronica/revistas/educacao_foco/artigos/ano2014/educacao_ambien tal.pdf > Acesso em: 1 mai. 2015.

SAUVÉ, L. Educação Ambiental e desenvolvimento sustentável: uma análise complexa. Revista Educação Pública, v. 6, n.10, p. 72-102, 1997. Disponível em: <http://www.ufmt.br/revista/arquivo/rev10/educacao_ambiental_e_desenvolvim.html.> Acesso em: 25 abr. 2015.

SILVA, A. A. e PASSERINO, L. M. A Fazenda Software Educativo para a Educação Ambiental. RENOTE- Revista Novas Tecnologias na Educação, Porto Alegre, v. 5, n.1, p. 1-12, dez. 2007.

SILVA, Valquiria Brilhador da; CRISPIN, Jefferson de Queiróz. Um Breve Relato Sobre a Questão Ambiental. GEOMAE - Geografia, Meio Ambiente e Ensino. Campo Mourão. v.2, n.1, p.163-175, $1^{\circ}$ sem/2011.

SORRENTINO, M. et al. Educação Ambiental como Política Pública. Educação e Pesquisa, São Paulo, v. 31, n. 2, p. 285-299, maio/ago. 2005.

FERREIRA, Máverick A. et al. NiceTown - Um Jogo Eletrônico para Ensino da Educação Ambiental. In: $3^{\circ}$ Congresso Brasileiro de Informática na Educação (CBIE 2014), 3; Workshop de Informática na Escola (WIE 2014), 20. 2014, Dourados-MT, Anais..., p. 298-307. Disponível em: < http://br-ie.org/pub/index.php/wie/article/viewFile/3112/2620>. Acesso em: 12 abr. 2015.

LOULA, Angelo $C$. et al. Modelagem Ambiental em um Jogo Eletrônico Educativo. In: BRAZILIAN SYMPOSIUM ON GAMES AND DIGITAL ENTERTAINMENT, 8, 2009, Rio de Janeiro, RJ Brazil, Anais..., p. 171-180. Disponível em: <http://www.sbgames.org/papers/sbgames09/culture/full/cult20_09.pdf>. Acesso em: 10 abr. 2015.

RODRIGUES, J. F.; CAMARGO, J. T. F.; VERSZTO. Desenvolvimento de jogos educativos para dispositivos portáteis para Educação Ambiental. Disponível em: < http://intercienciaesociedade.fmpfm.edu.br/colecao/online/v2_n2/5_desenvolvimento_de_jogos.pdf >. Acesso em: 07 mar. 2015. 